\title{
ESPÉCIES NOVAS DE PARACOLLETINI E PANURGINAE DO SUL DO BRASIL E ARGENTINA (HYMENOPTERA, APOIDEA) ${ }^{1}$
}

\author{
Danúncia Urban ${ }^{2}$
}

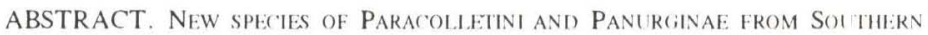
Brazil. ani) Argentina (Hymenoptera, Apoidea). Cephalocolletes Michener. 1989 (Paracolletini) is placed in a new status and new species are deseribed: Cephalocolletes isabelae, sp.n., Cephatocolletes rugata, sp.n. and Cephalocolletes crassipunctata, sp.n.: another Paracolletini bees, Bicolletes pampeana, sp.n. and Sarocolletes guaritarum. sp.n.. and the Panurginae Anthrenoides micans, sp.n..

KEY WORDS. Hymenoptera, Anthrenoides. Andrenidae. Cephalocolletes. Bicolletes. Sarocolletes, Colletidae, taxonomy
\end{abstract}

O estudo de exemplares coletados no Rio Grande do Sul por pesquisadores do convênio entre a Pontifícia Universidade Católica do Rio Grande do Sul (PUCRS) Brasil e a Universidade de Tübingen, Alemanha, e da Coleção de Entomologia Pe. Jesus S. Moure do Departamento de Zoologia da Universidade Federal do Paraná (DZUP), levou às descrições de cinco espécies novas de Paracolletini (Colletinae, Colletidae) e uma de Panurginae (Andrenidae).

\section{PARACOLleTINI}

\section{Cephalocolletes Michener, 1989, stat.n.}

Leioproctus (Cephalocolletes) Michener. 1989, Univ.Kansas Sci.Bull. 53 (11): 657.

Para Michener (1989) Leioproctus Smith, 1853 tem um sentido muito amplo, incluindo 18 suh-gêneros com vasta distrihuição geográfica: Austrália, Nova Caledônia, Nova Zelândia e América do Sul. Nestes sub-gêneros há estruturas bastante diferenciadas no tegumento, pilosidade, sétimo e oitavo esternos e genitália. Os esternos não expostos e a genitália, na publicação de Michener estão muito bem representados pelo grande número de figuras, mostrando grande variabilidade de formas. Optamos pela colocação de Cephalocolletes na categoria genérica, incluindo espécies novas, que tem em comum com a espécie tipo Cephalocolletes laticeps (Friese, 1906): tegumento sem brilho metálico: gálea com ápice largo arredondado, cerdas apicais e chanfro subapical no bordo anterior; palpos maxilares com dois artículos ultrapassando a gálea; asas anteriores com três células sub-marginais, a segunda pouco menor ou igual à terceira na margem posterior e recebendo a primeira recorrente além do meio da célula; segunda veia transversa cubital $\left(1^{\text {a }} \mathrm{r}-\mathrm{m}\right)$ curvada como a terceira transversa cubital; triângulo

1) Contribuiçâo número 886 do Departamento de Zoologia. Universidade Federal do Paraná.

2) Departamento de Zoologia. Universidade Federal do Paraná. Caixa Postal 19(120).81531-990) Curitiba, Paraná. Brasil. 
propodeal convexo, propódeo com rugas irregulares dôrso-ventrais na área próxima ao metepisterno eà coxa posterior; dimorfismo nos esporões tibiais posteriores, no macho os esporões micro-pectinados; na fêmea o esporão externo como no macho e o esporão interno pectinado, com poucos dentes (seis em C. laticeps); sétimo tergo sem placa pigidial no macho e com placa pigidial grande na têmea. No macho, segundo ao quarto esterno com franja pilosa fina e curta, quinto esterno com franja densa e longa, os pêlos muito longos nos flancos, voltados para o meio e com a ponta ondulada; sétimo e oitavo esternos e genitália com o mesmo padrão em C. laticeps e $C$. isabelae; o sétimo esterno com as placas laterais estreitas, alongadas e com tufo apical, as placas médias bilobadas, o lobo proximal grande e de aspecto triangular, com cerdas longas na margem, o lobo distal mais curto que as placas laterais e com tufo apical piloso.

Cephalocolletes laticeps distingue-se pelo porte maior, pilosidade toda preta, maior tamanho da cabeça, localização dos ocelos a meia distância entre o vértice e os alvéolos antenais e área supraclipeal denso-pontuada, convexa e pilosa. O macho sem dente suhapical nas mandíbulas e com a franja de pêlos do quinto esterno preta.

\section{Cephalocolletes isabelae, sp.n.}

Fig. 1

Diagnose. Pilosidade castanha no mesoscuto e escutelo, longa no macho e curta e densa na fêmea, restante da caheça e mesosoma com o branco predominando; faixas brancas apicais nos tergos basais; área supraclipeal brilhante, quase sem pontos, com depressão no sentido dorso-ventral e quase glabra no disco; esporão tibial posterior interno da fêmea com quatro dentes.

Holótipo fêmea. Tegumento preto, passando a castanho no lado ventral do flagelo a partir do quarto artículo; pernas com tíbias e basitarsos posteriores castanhos com o lado interno castanho mais claro; esternos castanhos com áreas enegrecidas.

Pilosidade branca na cabeça, porém castanha escura no vértice; hranca na base do mesoscuto, mesepisternos, metepisternos, metanoto e flancos do propódeo; restante do mesoscuto e escutelo castanhos; branca nos artículos basais das pernas, nas anteriores até o fêmur, nas medianas e nas posteriores também em parte da tíbia, nas demais áreas das pernas castanha enegrecida. Branca, longa e esparsa no primeiro tergo, do segundo ao quarto branca decumbente no ápice, formando faixa completa só no quarto e faixas laterais no segundo e terceiro; no disco destes tergos curta e enegrecida, semi-ereta; mais densa e alongada nos flancos ventrais dos tergos; no quinto e sexto tergos negra; nos esternos castanha.

Tergo basal com o tegumento brilhante, quase sem pontos na margem e com pontuação fína esparsa no disco.

Comprimento aproximado $10,17 \mathrm{~mm}$; comprimento da asa anterior $7,83 \mathrm{~mm}$; largura da cabeça $3,28 \mathrm{~mm}$; comprimento do olho $1,96 \mathrm{~mm}$; distância interorhital superior $2,20 \mathrm{~mm}$ e a inferior $2,04 \mathrm{~mm}$. 


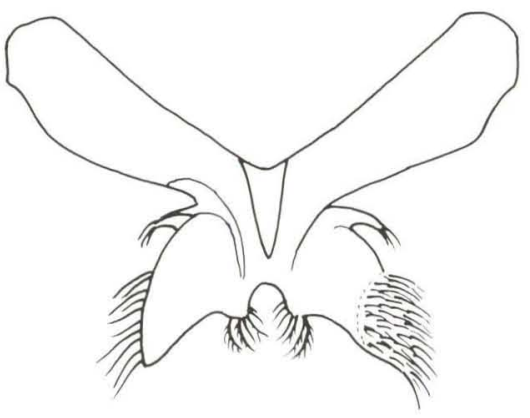

1

Figs 1-2. Sétimo esterno do macho. (1) Cephalocolletes isabelae, sp.n.; (2) Bicolletes pampeana, sp.n.

Alótipo macho. Tegumento preto, antena castanho-amarelada a partir de pequena área apical do segundo flagelômero no lado ventral; pernas castanhoenegrecidas com coxas e trocanteres pretos.

Pilosidade branca na cabeça; castanha e longa no mesoscuto e escutelo, branca no restante do mesosoma, também longa no metanoto; branca nas pernas, nos três tergos basais e nos quatro esternos basais; no quarto e quinto tergos castanha; no sexto e sétimo quase preta, a pilosidade dos tergos semi-ereta na base e disco e decumbente formando faixas apicais não densas do segundo ao quarto, um pouco amarelada no quinto; no quinto esterno a longa franja levemente amarelada, sex to esterno com pêlos curtos castanhos.

Sétimo esterno com área cerdosa na metade apical do lobo proximal da placa média (Fig. 1); em C. laticeps o sétimo esterno sem esta área cerdosa.

Comprimento aproximado $9,2 \mathrm{~mm}$; comprimento da asa anterior 7,08mm; largura da cabeça $3,0 \mathrm{~mm}$; comprimento do olho $1,80 \mathrm{~mm}$; distância interorbital superior $2,0 \mathrm{~mm}$ e a inferior $1,64 \mathrm{~mm}$.

Holótipo fêmea e alótipo macho. Brasil, Rio Grande do Sul: Capão da Canoa (Arroio Teixeira), 22-XI-1991, I. Alves dos Santos leg. . Parátipos - duas fêmeas e dois machos com os mesmos dados do holótipo; um macho da mesma localidade e coletor, 18-X-92; Santa Catarina: Pântano do Sul, 7-XI-59, oito fêmeas e três machos, P.D. Hurd leg.; depositados na Coleção de Entomologia Pe. J.S. Moure, (DZUP). Onze machos com os mesmos dados do holótipo, da mesma localidade e coletor; 17-XI-91, três machos; 15-XII-91 cinco fêmeas e dois machos; 18-X-92, seis fêmeas e dois machos; 5-XII-92, dois machos; 22-XII-92, um macho e uma fêmea; 28-X-93, um macho; 7-XI-93, quatro fêmeas; depositados no Laboratório de Pesquisas Biológicas (PUCRS).

Distribuição geográfica. BRASIL: Rio Grande do Sul e Santa Catarina.

Espécie dedicada à pesquisadora Isabel Alves dos Santos que coletou o material e se dedica ao estudo das abelhas e suas visitas às plantas. 


\section{Cephalocolletes rugata, sp.n.}

Diagnose. Fêmea com pilosidade densa e curta, fulva, de comprimento uniforme encobrindo o tegumento no mesoscuto e escutelo; metanoto com pêlos longos; quatro primeiros tergos com faixa branca apical; área supraclipeal brilhante e sem pontos no disco, convexa; esporão tibial posterior interno com quatro dentes.

Holótipo fềmea. Tegumento preto com área castanho-avermelhada no disco das mandíhulas; lado ventral dos flagelômeros castanho a partir do quarto artículo; tégulas amarelo-acastanhadas brilhantes; pernas castanho-enegrecidas e esternos basais com área amarela acastanhada. Asas escurecidas na ponta.

Pilosidade branca na cabeça; fulva, curta, densa e uniforme encobrindo o tegumento no mesoscuto e escutelo, mais clara e alongada nos lohos pronotais, demais áreas do mesosoma brancas; pernas com pêlos hrancos nos artículos basais e lado interno das tíhias, o lado externo castanho escuro; nas posteriores os pêlos longos finos ramificados também brancos e com estria castanha partindo da placa basitibial; basitarsos anteriores e medianos castanhos com o lado interno méleo; basitarsos posteriores brancos no lado externo. Branca no primeiro tergo, longa e muito esparsa no disco formando franja no bordo, do segundo ao quarto branca nos flancos e margem, e no disco preta e curta; no quinto e sexto tergos preta; escopa ventral castanha clara.

Tergo basal brilhante com pontuação fina no bordo, área discal com pontos pequenos muito esparsos.

Variações. Presença de pilosidade castanha no ápice do clípeo e mais amarelada do mesoscuto e escutelo.

Comprimento aproximado $10,5 \mathrm{~mm}$; comprimento da asa anterior $7,33 \mathrm{~mm}$; largura da cabeça $3,28 \mathrm{~mm}$; comprimento do olho $1,88 \mathrm{~mm}$; distância interorhital superior $2,20 \mathrm{~mm}$ e a inferior $1,98 \mathrm{~mm}$.

Holótipo fêmea. Brasil, Rio Grande do Sul: Caçapava do Sul (Guaritas), 06-XI-1991, C. Schlindwein leg.. Parátipos - Rio Grande do Sul: Santana da Boa Vista (Guaritas), 13-XI-92, três fêmeas, C. Schlindwein leg.; ARgEnTINA, Entre Rios: Puerto Marguez (Márquez $=$ La Paz), XI-1950, duas fêmeas, J. Foerster leg.; depositados na Coleção de Entomologia Pe. J.S. Moure (DZUP). Parátipos. Rio Grande do Sul: Santana da Boa Vista (Guaritas), 13-XI-92, duas fêmeas, C. Schlindwein leg.; 14.XI.91, uma fêmea, Schlindwein leg.; Canguçu, 18-XI-89, uma fêmea, C. Schlindwein leg.; Bagé, 02-XI-92, duas fêmeas, C. Schlindwein leg.; Taim, 05.XII.86, uma fêmea, R. Radtke leg.; depositados no Lahoratório de Pesquisas Biológicas (PUCRS).

Distribuição Geogrática. Brasil: Rio Grande do Sul, Argentina: Entre Rios.

Etimologia. O nome da espécie é alusivo às rugas laterais do propódeo. 


\section{Cephalocolletes crassipunctata, sp.n.}

Diagnose. Fêmea com pilosidade densa, fulva clara e uniforme encobrindo o tegumento no mesoscuto e escutelo, mais pálida e também curta no disco do metanoto; tergos com faixa apical branca; área supraclipeal pilosa e densopontuada, convexa; esporão tibial interno com quatro dentes.

Holótipo fêmea. Tegumento preto, passando a castanho no disco das mandíbulas, lado ventral dos flagelômeros, tégulas e tarsômeros distais. Asas translúcidas, não escurecidas na ponta.

Pilosidade branca na cabeça, castanho-clara no vértice; de um fulvo claro no mesoscuto e escutelo, os pêlos curtos, densos e uniformes encobrindo o tegumento; parte mediana do metanoto também com pilosidade uniforme densa e curta, distinta das adjacências e esbranquiçada; propódeo e mesepisternos brancos; branca nos artículos basais das pernas, castanha no lado externo das tíbias e basitarsos, lado ventral dos basitarsos castanho-amarelado. No primeiro tergo esparsa e alongada; formando faixas laterais brancas de pêlos curtos decumbentes no segundo e terceiro e, faixa completa no quarto, os pêlos brancos longos nos flancos dos tergos; quinto e sexto enegrecidos; escopa ventral castanha, pêlos esbranquiçados nos esternos basais.

Tergo basal brilhante, com pontuação densa e grossa no disco e margem, no segundo tergo os pontos pouco menores, borda do tergo com a mesma pontuação do disco.

Comprimento aproximado $8,75 \mathrm{~mm}$; comprimento da asa anterior $6,83 \mathrm{~mm}$; largura da cabeça $2,80 \mathrm{~mm}$; comprimento do olho $1,60 \mathrm{~mm}$; distância interorbital superior $1,92 \mathrm{~mm}$ e a inferior $1,56 \mathrm{~mm}$.

Holótipo fêmea. Argentina, Catamarca: Campo de Pucara, 11-XI-1951, Juan Foerster leg. Parátipos - uma fêmea, com os mesmos dados do holótipo; Catamarca: uma fêmea, 08-XII-51, Martinez leg.; depositados na Coleção de Entomologia Pe. J.S. Moure (DZUP).

Distribuição geográfica. ARgentina: Catamarca.

Etimologia. O nome da espécie é alusivo à pontuação densa do tergo basal.

\section{Sarocolletes guaritarum, sp.n.}

Diagnose. Fêmea com pilosidade fulva no mesoscuto, escutelo e metanoto, branca nos tergos formando faixas apicais decumbentes, castanha na escopa esternal e nas tíbias posteriores; asas escurecidas na ponta.

Holótipo fêmea. Tegumento preto com o flagelo castanho ventralmente a partir do quarto flagelômero. Asas méleas na parte basal e com um banho escuro na ponta, veias castanhas e a $\mathrm{R}$ preta.

Pilosidade branca na cabeça passando a amarela acastanhada no vértice; fulva no mesoscuto, escutelo e metanoto e esbranquiçada no restante do mesosoma; branca nas coxas, trocânteres e fềmures, no restante das pernas predomina o castanho, de uma tonalidade pálida nas tíbias anteriores e medianas e muito escuro 
nas posteriores. Branca nos quatro tergos basais, decumbente na margem formando faixas, curta e ereta no disco do segundo ao quarto; quinto e sexto tergos pretos; escopa ventral castanha.

Comprimento aproximado $10,0 \mathrm{~mm}$; comprimento da asa anterior $7,67 \mathrm{~mm}$; largura da cabeça $3,40 \mathrm{~mm}$; comprimento do olho $2,0 \mathrm{~mm}$; distância interorbital superior $2,10 \mathrm{~mm}$ e a inferior $2,0 \mathrm{~mm}$.

Holótipo fêmea. Brasil, Rio Grande do Sul: Caçapava do Sul (Guaritas), 23.X.1992, C. Schlindwein leg. Parátipos - duas fêmeas, com os mesmos dados do holótipo; depositados na Coleção de Entomologia Pe. J.S. Moure (DZUP). Parátipos. Rio Grande do Sul: Caçapava do Sul (Minas de Camaquã), uma fềmea, 25-X-90, S.W. Freitas leg.; uma fêmea, 10-XI-90, C. Schlindwein leg.; uma fềmea, 14-X-90, C. Schlindwein leg.; depositados no Laboratório de Pesquisas Biológicas (PUCRS).

Distribuição Geográfica. Brasil: Rio Grande do Sul.

Etimologia. O nome da espécie é alusivo às guaritas, formações geológicas da região em que foram coletados alguns dos exemplares.

Comentário. Espécie muito parecida com Sarocolletes rufipennis (Cockerell, 1917) de Catamarca e Córdoba (Argentina), porém, S. rufipennis tem as asas com leve tonalidade mélea, sem escurecimento apical, escopa ventral cremosa e pilosidade muito clara nas pernas.

\section{Bicolletes pampeana, sp.n.}

Fig. 2

Diagnose. Tegumento preto sem brilho metálico, pontuação densa e grossa na cabeça, fïna nos tergos, micro-reticulada; macho com franja pilosa do quinto esterno mais longa nos lados, os pêlos arqueados para o meio; fêmea com cerdas lisas castanhas semi-eretas na escopa ventral.

Holótipo macho. Tegumento preto, antena com amarelo acastanhado por baixo em pequena área no segundo flagelômero e mais largamente nos restantes; tarsômeros medianos e distais com áreas amarelo-acastanhadas.

Pilosidade branca predominando. Densa e longa na cabeça e mesosoma, um pouco cremosa no mesoscuto e escutelo; lado ventral dos basitarsos de um amarelo méleo; branca, longa e esparsa no primeiro tergo, do segundo ao quinto muito curta e semi-decumbente, castanha nos dois tergos apicais; esparsa nos esternos e formando franja rala no bordo do segundo ao quarto esterno, neste pouco mais longa nos flancos e com os pêlos voltados para o meio, no quinto, a franja mais densa com pêlos longos nos flancos e encurvados para o meio e pouco mais curtos no meio do esterno, os pêlos maiores tão longos como o próprio tergo.

Pontuação densa e grossa na cabeça, o tegumento brilhante porém com micro-reticulação; mesoscuto sem micro-reticulação, com pontos mais esparsos no quarto posterior; esparsa na base do escutelo; muito densa nas áreas laterais do propódeo, sulco espiracular com trabéculas longas na metade basal, triângulo propodeal micro-reticulado com rúgulas nos cantos basais; tergos e esternos com 
micro-reticulação e pontuação densa deixando margem estreita sem pontos nos tergos.

Comprimento aproximado $8,67 \mathrm{~mm}$; comprimento da asa anterior $5,83 \mathrm{~mm}$; largura da cabeça $2,67 \mathrm{~mm}$; comprimento do olho $1,56 \mathrm{~mm}$; distância interorbital superior $1,62 \mathrm{~mm}$ e a inferior $1,40 \mathrm{~mm}$.

Alótipo fêmea. Tegumento como no macho. Pilosidade mais escura. Branca na cabeça, com mescla de castanho no vértice; mesoscuto e escutelo castanhoescuros; lobos pronotais com mescla de castanho claro e branco; mesepisternos castanhos na metade anterior, na face ventral com cerdas lisas méleas; branca nas demais áreas do mesosoma; nas pernas predomina o castanho, com tonalidade mais clara e amarelada no lado ventral dos basitarsos anteriores e posteriores, nos medianos enegrecida; branca do primeiro ao quarto tergo, castanho-enegrecida nos dois distais e nos esternos, do segundo ao quarto esterno com cerdas longas lisas de tamanho irregular e com pêlos plumosos somente nos cantos, no quinto e sexto esternos com pêlos plumosos.

Comprimento aproximado $9,17 \mathrm{~mm}$; comprimento da asa anterior $5,92 \mathrm{~mm}$; largura da cabeça 2,76mm; comprimento do olho $1,76 \mathrm{~mm}$; distância interorbital superior $1,80 \mathrm{~mm}$ e a inferior $1,68 \mathrm{~mm}$.

Holótipo macho. Brasil, Rio Grande do Sul: Caçapava do Sul (Guaritas), 08.X.1991, C. Schlindwein leg. Alótipo fêmea, 11-X-91, com os mesmos dados. Parátipos da mesma localidade e coletor: um macho, 08-X-91; uma fêmea, 09-X-91; um macho, 11-X-91; depositados na Coleção de Entomologia Pe. J.S. Moure (DZUP). Parátipos da mesma localidade e coletor do holótipo: uma fêmea, 13-X-91; um macho, 07-XI-91; uma fêmea, 09-XI-91; dois machos, 23-X-92; Caçapava do Sul, Minas de Camaquã, mesmo coletor: uma fêmea, 25-X-90; uma fêmea, 26-X-90; depositados no Laboratório de Pesquisas Biológicas (PUCRS).

Distribuição geogrática. BRAsıl: Rio Grande do Sul.

Etimologia. O nome da espécie é alusivo à região dos pampas.

Comentário. Esta espécie aproxima-se de Bicolletes franki Friese, 1908 pelo comprimento da área pós-palpal da gálea, bem mais curta que o palpo maxilar, alcançando o terceiro artículo, gálea com o ápice arredondado largo com chanfro na parte subapical anterior; o macho, pela franja do quinto esterno e a fêmea, pelas cerdas lisas semi-decumbentes da escopa ventral. Bicolletes fianki tem sulco espiracular com trabéculas longas em toda extensão, brilho metálico azulado, densa pontuação nos tergos e também foi coletada em Caçapava do Sul.

Embora Michener (1989) tenha proposto Perditomorpha Ashmead, 1899 como sub-gênero de Leioproctus, para numerosas espécies, incluindo Bicolletes neotropica Friese, 1908, espécie tipo de Bicolletes, as numerosas exceções apresentadas no citado trabalho justificam a colocação da espécie neste gênero.

\section{PANuRginaE}

\section{Anthrenoides micans, sp.n.}

Diagnose. Tegumento preto, com pequena nódoa amarela na hase das tíbias anteriores e medianas, no macho também nas posteriores e com amarelo também 
no labro, clípeo e paroculares inferiores; tegumento densamente micro-pontuado na depressão pré-marginal dos tergos. Macho com recorte mediano estreito e profundo no sexto esterno, com os lobos laterais um pouco projetados para baixo. Fêmea com fóvea facial brilhante mais larga superiormente.

Holótipo macho. Tegumento preto com labro, clípeo e paroculares inferiores amarelos, clípeo com duas pequenas nódoas pretas arredondadas próximas às fóveas tentoriais e margem estreita castanha, também o labro com margem castanha; flagelo amarelo-acastanhado por baixo; pequena nódoa amarela na base das tíbias, nas posteriores limitada à placa basitibial com orla preta; nas tíbias anteriores a nódoa amarela prolongada em área amarela acastanhada em toda a face anterior.

Pilosidade branca e curta, mais alongada na cabeça, semi-decumbente e densa na área ventral dos mesepisternos, alongada formando franja rala no sexto tergo e nos flancos do sétimo, neste, mais densa e voltada para o meio; amarelada no lado ventral dos basitarsos.

Fóveas faciais brilhantes, muito estreitas e pouco mais longas que o diâmetro dos flagelômeros apicais. Base do propódeo com trabéculas irregulares em uma área delimitada por fraca elevação. Pontuação mais esparsa no labro, clípeo, área supraclipeal e paroculares inferiores, muito densa e com microreticulação no restante da cabeça; nos esternos os pontos maiores do que nos tergos, nestes com depressão pré-marginal densamente micro-pontuada; sétimo tergo com pequena elevação mediana expandida para a base em forma triangular.

Comprimento aproximado $7,33 \mathrm{~mm}$; comprimento da asa anterior $4,52 \mathrm{~mm}$; largura da cabeça $2,20 \mathrm{~mm}$; comprimento do olho $1,30 \mathrm{~mm}$; distância interorbital superior $1,46 \mathrm{~mm}$ e a inferior $1,70 \mathrm{~mm}$ (no limite inferior do olho).

Alótipo fêmea. Tegumento preto, flagelo castanho amarelado por baixo, tíbias anteriores e medianas com nódoa basal amarela.

Pilosidade branca, pouco alongada na cabeça e nas franjas esternais; levemente amarelada nas cerdas finas com ápice em gancho, da face ventral dos mesepisternos e no lado ventral dos basitarsos medianos e posteriores, nos anteriores mais castanha; escopas tibiais com cerdas brancas lisas; fímbria do quinto tergo castanha; sexto tergo com pilosidade densa alongada amarelo-fulva.

Fóveas faciais brilhantes, bem maiores que no macho, com a margem justaorbital reta e levemente arqueada no lado frontal, no ponto mais largo quase igua lando o diâmetro do ocelo mediano e o comprimento quase três vezes o mesmo diâmetro. Clípeo brilhante com pontos grandes.

Comprimento aproximado $7,50 \mathrm{~mm}$; comprimento da asa anterior $5,0 \mathrm{~mm}$; largura da cabeça $2,24 \mathrm{~mm}$; comprimento do olho $1,60 \mathrm{~mm}$; distância interorbital superior $1,40 \mathrm{~mm}$ e a inferior $1,60 \mathrm{~mm}$ (no limite inferior do olho).

Holótipo macho. BrasiL, Rio Grande do Sul: Santana da Boa Vista (Guaritas), 13-XI-1992, C. Schlindwein leg.. Alótipo fềmea, um parátipo macho e três fềmeas com a mesma etiqueta de procedência do holótipo depositados na Coleção de Entomologia Pe. J.S. Moure (DZUP). Dois parátipos machos e uma fềmea da mesma localidade e mesmo coletor do holótipo, 10-XI-91; Rio Grande 
do Sul: Caçapava do Sul (Minas de Camaquã), um macho, 10-X-90, C. Schlindwein leg.; um macho, 11-XI-90; uma fêmea, 21-X-90; depositados no Laboratório de Pesquisas Biológicas (PUCRS).

Distibuição geográfica. Brasil: Rio Grande do Sul.

Etimologia. O nome da espécie indica o brilho do tegumento.

Comentário. Exemplares de Anthrenoides meridionalis (Schrottky, 1906), coletados no Paraná, Santa Catarina e Rio Grande do Sul, foram estudados e diferem da espécie ora proposta como nova pela fraca micro-reticulação da depressão marginal dos tergos; os machos, pelo labro preto, nódoa amarela na base das tíhias anteriores e medianas, pela placa basitibial preta e, pelo recorte circular largo e profundo do sexto esterno.

AGRADECIMENTOS. À Isabel Alves dos Santos e Clemens Schlindwein pela doação do material para estudo e ao Prof. Pe. Jesus S. Moure, pelo acesso à bibliografia .

\section{REFERÊNCIAS BIBLIOGRÁFICAS}

Cockerell, T.D.A. 1917 LIV. Descriptions and Records of Bees LXXVIII. Ann. \& Mag. Nat. Hist. 20 (8): 436-441.

FRIESE, H. 1908. Die Apidae (Blumenwespen) von Argentina nach den Reisenergebnissen der Herren C. Jensen-Haarup und P. Joergensen in den Jahren 1904-1907. Flora og Fauna 10: 1-94.

MiChENER, C.D. 1989. Classification of American Colletinae (Hymenoptera, Apoidea). Univ. Kansas Sci. Bull. 53 (11): 622-703.

SchrotTky, C. 1906. Neue und wenig bekannte sudamerikanische Bienen Zeitschr. Hym. Dipt. 6: 305-316. 